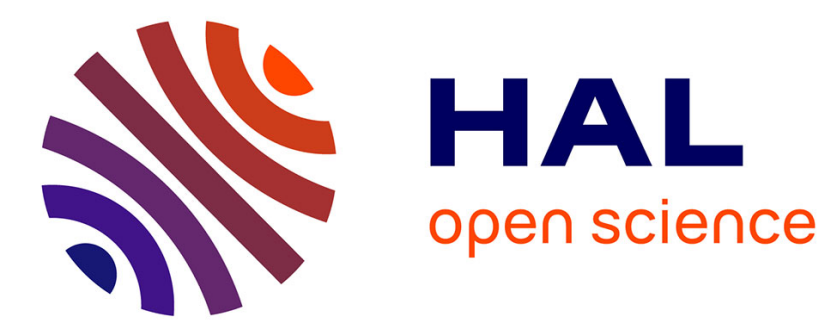

\title{
Hands on Native Mass Spectrometry Analysis of Multi-protein Complexes
}

Stéphane Erb, S Cianférani, Julien Marcoux

\section{To cite this version:}

Stéphane Erb, S Cianférani, Julien Marcoux. Hands on Native Mass Spectrometry Analysis of Multiprotein Complexes. Methodes in molecular biology, pp.173-191, 2021. hal-03056883

\section{HAL Id: hal-03056883 \\ https://hal.science/hal-03056883}

Submitted on 11 Dec 2020

HAL is a multi-disciplinary open access archive for the deposit and dissemination of scientific research documents, whether they are published or not. The documents may come from teaching and research institutions in France or abroad, or from public or private research centers.
L'archive ouverte pluridisciplinaire HAL, est destinée au dépôt et à la diffusion de documents scientifiques de niveau recherche, publiés ou non, émanant des établissements d'enseignement et de recherche français ou étrangers, des laboratoires publics ou privés. 


\title{
Chapter XX
}

\section{Hands on Native Mass Spectrometry Analysis of Multi-protein Complexes.}

\author{
Stéphane Erb, S. Cianférani and Julien Marcoux
}

\begin{abstract}
By maintaining intact multi-protein complexes in the gas-phase, native mass spectrometry provides their molecular weight with very good accuracy compared to other methods (typically native PAGE or SEC-MALS) [1]. Besides, heterogeneous samples, both in terms of oligomeric states and ligand-bound species can be fully characterized. Here we thoroughly describe the analysis of several oligomeric protein complexes ranging from a $16 \mathrm{kDa}$ dimer to a $801 \mathrm{kDa}$ tetradecameric complex on different instrumental setups.
\end{abstract}

Key words Structural Mass Spectrometry, Non Covalent Mass Spectrometry, Oligomeric states, Stoichiometry, Subcomplexes

\section{Introduction}

Mass spectrometry (MS) plays a pivotal role for the characterization of multi-protein complexes. Routinely coupled with reversed-phase liquid chromatography (LC-MS), it allows purity and homogeneity assessment of biological complexes. Classical LC-MS workflow require organic solvents (usually $\mathrm{H}_{2} \mathrm{O}$ /acetonitrile) and acidic conditions (e.g. acetic or formic acid) to achieve best chromatographic resolutions along with optimal MS detection. However those experimental conditions induce multi-protein noncovalent complexes' dissociation. In the early 90s, MS approaches performed in ammonium acetate buffer maintaining quaternary structures of multi-protein complexes have been first described [2-4], opening the way for a new field of application called noncovalent or "native" MS [5,6]. By transferring intact noncovalent assemblies into the gas phase of the mass spectrometer, native MS enables multi-protein complex stoichiometry assessment thanks to accurate mass measurements. Mostly performed on TOF and Q-TOF [7] instruments in its early years, it has recently benefited from technological improvements to reach high resolution native MS [8]. Native MS is currently implemented in most structural biology departments to complement conventional structural biophysical techniques like crystallography, electron microscopy, NMR or SAXS. The methodology is versatile as any type of multi-protein complex can be analyzed, ranging from homo-oligomeric proteins [5] to hetero-oligomers $[9,10]$ or even protein/nucleic assemblies $[11,12]$ and membrane complexes $[13,14]$. Latest methodological breakthroughs in the field include the direct analysis of complexes from cell lysates [15] or from native membranes [14] and the release of a new instrument enabling the complete analysis of very large complexes with unprecedented resolution [16].

In this chapter we illustrate the possibilities of native MS on different types of multi-protein complexes and different MS platforms to assess stoichiometries. Data interpretation is usually performed by comparing the masses of the individual subunits of the complexes obtained by classical MS analysis in denaturing conditions and the mass of the intact noncovalent multi-protein assembly measured in native conditions. 


\section{Materials}

Prepare all solutions using deionized water and analytical grade reagents. Prepare and store all reagents at $4^{\circ} \mathrm{C}$.

2.1 Desalting

1. Ammonium acetate: $200 \mathrm{mM}$ solution in water (Note 1). Weigh $1.54 \mathrm{~g}$ ammonium acetate $(>98 \%)$ and transfer to a $100 \mathrm{~mL}$ cylinder. Add water to a volume of 95 $\mathrm{mL}$. Mix and adjust pH to 7.4 with ammonium hydroxide (see Note 2). Make up to $100 \mathrm{~mL}$ with water.

2.2 Cesium iodide calibration mix

Resuspend cesium iodide powder in 50/50 isopropanol/water (v/v) to a final concentration of $2 \mathrm{mg} / \mathrm{mL}$.

2.3 Ammonium hexafluorophosphate calibration mix

Resuspend ammonium Hexafluorophosphate powder in 50/50 isopropanol/water $(\mathrm{v} / \mathrm{v})$ to a final concentration of $1 \mathrm{mg} / \mathrm{mL}$.

2.4 GroEL reconstitution

GroEl must be freshly prepared.

1. Prepare $9.445 \mathrm{~mL}$ of $1 \mathrm{M}$ Tris-acetate by weighting $1.21 \mathrm{~g}$ of Tris-base and atop up to $10 \mathrm{~mL}$ with acetic acid.

2. Prepare $10 \mathrm{~mL}$ of reconstitution buffer, composed as follows: $200 \mu \mathrm{L}$ Tris-acetate at $1 \mathrm{M}$ previously prepared, $50 \mu \mathrm{L}$ EDTA at $100 \mathrm{mM}, 10.7 \mathrm{mg}$ magnesium acetate tetrahydrate, $5.5 \mathrm{mg}$ ATP, $37.3 \mathrm{mg}$ potassium chloride to reach final concentrations of $20 \mathrm{mM}, 0.5 \mathrm{mM}, 5 \mathrm{mM}, 1 \mathrm{mM}$ and $50 \mathrm{mM}$, respectively.

3. Prepare a $200 \mathrm{mM}$ ammonium acetate solution $\mathrm{pH} 6.9$ by weighting $770.8 \mathrm{mg}$ in $50 \mathrm{~mL}$.

4. Reconstitute GroEL (Chaperonin 60 from Escherichia coli, Sigma-Aldrich reference $\mathrm{n}^{\circ} \mathrm{C} 7688$ ) powder $(1 \mathrm{mg})$ by adding $80 \mu \mathrm{L}$ of refolding buffer and $20 \mu \mathrm{L}$ of methanol directly into the vial.

5. Shake for $2 \mathrm{~h}$ a room temperature.

6. Transfer the entire volume into an Eppendorf, add $100 \mu \mathrm{L}$ acetone and agitate gently.

7. After $2 \mathrm{~min}$, centrifuge for $1 \mathrm{~min}$ at $11,000 \mathrm{rpm}$ : a white precipitate should be present. Delete the supernatant. Then, add $200 \mu \mathrm{L}$ of refolding buffer and agitate gently until complete dissolution.

8. Shake for 1 hour at room temperature. Centrifuge for $1 \mathrm{~min}$ at $1,500 \mathrm{~g}$ and take the supernatant to perform the first desalting step as explained in 3.1 (on Zeba $^{\mathrm{TM}}$ spin column).

9. The second desalting step is performed as explained in 3.2 with 10 cycles (each one takes between 8-15 min) at 4,500 rmp with a $50 \mathrm{kD}$ MWCO membrane. Finally, check the protein concentration by UV absorbance at $280 \mathrm{~nm}$. Typically, approximatively $10 \mu \mathrm{M}$ of 14 -mer should be obtained $\left(\varepsilon=10,430 \mathrm{M}^{-1} . \mathrm{cm}^{-1}\right.$ for GroEL monomer at $280 \mathrm{~nm}$ ).

\section{Methods}

3.1 Benchtop Size Exclusion Chromatography desalting

1. Operate at $+4^{\circ} \mathrm{C}$.

2. You can use $6 \mathrm{~K}$ MWCO Micro Bio-Spin ${ }^{\mathrm{TM}} 6$ (Biorad) or $0.5 \mathrm{~mL} 7 \mathrm{~K} \mathrm{MWCO} \mathrm{Zeba}{ }^{\mathrm{TM}}$ (ThermoFisher Scientific) spin columns.

3. Remove the storage solution by 2 min centrifugation at $1,000 \mathrm{~g}$ for Micro BioSpin ${ }^{\mathrm{TM}}$ columns and $1 \mathrm{~min}$ at $1,500 \mathrm{~g}$ for $\mathrm{Zeba}^{\mathrm{TM}}$ columns. 
4. Equilibrate the columns by adding $500 \mu \mathrm{L}$ (Micro Bio-Spin ${ }^{\mathrm{TM}}$ ) or $300 \mu \mathrm{L}\left(\right.$ Zeba $^{\mathrm{TM}}$ ) of $200 \mathrm{mM}$ ammonium acetate solution, centrifuge for $1 \mathrm{~min}$ at $1,000 \mathrm{~g}$ (Micro BioSpin $\left.^{\mathrm{TM}}\right)$ or at $1,500 \mathrm{~g}\left(\mathrm{Zeba}^{\mathrm{TM}}\right)$ and discard the eluate.

5. Repeat step 3 thrice.

6. Load between 20-75 $\mu \mathrm{L}$ (Micro Bio-Spin ${ }^{\mathrm{TM}}$ ) or $30-130 \mu \mathrm{L}\left(\mathrm{Zeba}^{\mathrm{TM}}\right.$ ) of sample. Loading smaller volume may affect recovery (Note 3).

7. Place the column in a $1 \mathrm{~mL}$ eppendorf tube and elute the desalted proteins by centrifuging $4 \mathrm{~min}$ at $1,000 \mathrm{~g}$ (Micro Bio-Spin ${ }^{\mathrm{TM}}$ ) or $2 \mathrm{~min}$ at $1,500 \mathrm{~g}\left(\mathrm{Zeba}^{\mathrm{TM}}\right)$

3.2 Ultrafiltration desalting

1. Operate at $+4^{\circ} \mathrm{C}$.

2. After selecting the appropriate MWCO of the ultrafiltration device, equilibrate its membrane with $500 \mu \mathrm{L}$ of $200 \mathrm{mM}$ ammonium acetate. Typical devices include Amicon $^{\mathrm{TM}}$ Ultra $0.5 \mathrm{~mL}$ or Vivaspin ${ }^{\mathrm{TM}} 500$ centrifugal concentrators (Merck). Centrifuge at $10,000 \mathrm{~g}$ for $30 \mathrm{sec}$, discard the eluate and repeat thrice.

3. Load your sample (up to $500 \mu \mathrm{L}$ )

4. Concentrate down to $50 \mu \mathrm{L}$ at $10,000 \mathrm{~g}$. Make up to $500 \mu \mathrm{L}$ with $200 \mathrm{mM}$ ammonium acetate and repeat five times this dilution/concentration cycle.

3.3 Direct infusion of the sample with the TriVersa Nanomate ${ }^{\mathrm{TM}}$ (Advion)

1. In the interface setting panel, set the controller power On and the temperature to $4^{\circ} \mathrm{C}$ (Note 4).

2. Load $10 \mu \mathrm{L}$ of desalted protein sample to the 96 or 384 -well plate.

3. In the Spray Optimization panel, set the Sample Volume to $5 \mu \mathrm{L}$, the gas pressure to 0.35 psi, the Voltage to apply to $1.60 \mathrm{kV}$ and press "Deliver Sample" (Note 5).

3.4 Calibration

3.4.1 Synapt G2 and G2Si

1. Using the TriVersa Nanomate ${ }^{\mathrm{TM}}$ (see 3.3), deliver $5 \mu \mathrm{l}$ of cesium iodide calibration mix (see 2.2).

2. In MassLynx MS Tune windows manually set the following parameters:

Operate the instrument in positive and sensitivity modes with a $\mathrm{m} / \mathrm{z}$ range from 1,000 to 8,000 .

Nanoflow+ panel: Sampling Cone: 150 V. Source Offset: 30V. Source Temperature: $80^{\circ} \mathrm{C}$. The Capillary Voltage and the gas flows are not used in the TriVersa Nanomate ${ }^{\mathrm{TM}}$ interface setup.

Instrument: Trap and Transfer Collision Energy are turned off (4V and $2 \mathrm{~V}$, respectively by default).

Save these parameters as an .ipr file.

3. Press "acquire" to start a 2 min TOF-MS acquisition in the $1000-8,000 \mathrm{~m} / \mathrm{z}$ range.

4. Average the signal over the $2 \mathrm{~min}$ in the Chromatogram panel and in the Spectrum panel, select Process\Automatic Peak Detection with the "Set Peak Detection Parameters Automatically" option activated.

5. Click on FilelSave Spectrum and click OK.

6. In the Acquity UPLC Console, click on Intellistart, select "Create Calibration" and click Start.

7. In the calibration profile editor, select the right Mass Calibration Profile (here Csl in the 1,000-8,000 m/z range), right click and reset it.

8. Right Click and edit the Mass Calibration Profile. Below the Positive Polarity chart, click on edit. Select the right Reference Compound (here "CsI_1000- 
8000 (positive) with reference masses ranging from 1,172.1450 $\mathrm{Da}$ to 7,927.2031 Da (Note 6).

9. Browse to select the previous acquisition file. Click on History and select the last AccMass2 line.

10. Close the 4 windows by clicking OK and close the Mass Calibration Profile Editor.

11. Click Next, Next and Start to launch the calibration.

\subsubsection{Q-Exactive ${ }^{\mathrm{TM}}$ Biopharma Orbitrap}

1. Using the syringe pusher to deliver the ammonium hexafluorophosphate calibration $\mathrm{mix}$ at $5 \mu \mathrm{l} / \mathrm{min}$.

2. In the Calibration Panel, select "HMR Mode calibration (pos)".

\subsubsection{LCT (upgraded for high mass detection by MS Vision)}

1. Using the TriVersa Nanomate ${ }^{\mathrm{TM}}$ (see 3.3), deliver $5 \mu$ l of cesium iodide calibration $\operatorname{mix}$ (see 2.2).

2. In MassLynx MS Tune window, manually set the following parameters:

Operate the instrument in positive mode with a m/z range from 1,000 to 10,000. Apply $120 \mathrm{~V}$ and $5 \mathrm{~V}$ for the sampling cone and extraction cone, respectively. The source temperature is set at $90^{\circ} \mathrm{C}$ but the capillary voltage and the gas flows are not used in the TriVersa Nanomate ${ }^{\mathrm{TM}}$ interface setup.

3. Adjust the backing pressure to 6 mbar (Note 7).

4. Start a 2 min acquisition with 4 sec scans.

5. Average the signal over the $2 \mathrm{~min}$ in the Chromatogram panel and in the Spectrum panel, select "Tools" then "Make Calibration" and select "Csl_esi.ref" profil. Adjust calibration points for the $\mathrm{m} / \mathrm{z}$ range targeted and click on FilelSave Spectrum then click OK and finally accept the calibration after closing the window.

6. Do not forget to load this calibration file (e.g. named Csl_date) before starting the first acquisition of the analyzed sample. To do so, click on "Acquire", then select "calibration" and load the calibration file. Finally perform the acquisition.

\subsubsection{Maxis II}

1. Using the HESI source and the $500 \mu \mathrm{L}$ Hamilton ${ }^{\mathrm{TM}}$ syringe, deliver cesium iodide calibration mix (see 2.2) with a flow rate set to $3 \mu \mathrm{L} / \mathrm{min}$.

2. In the MS Tune window, manually set the following parameters:

Operate the instrument in positive mode with a $\mathrm{m} / \mathrm{z}$ range from 1,000 to 8,000 . Apply $20 \mathrm{eV}$ and $5 \mathrm{eV}$ for isCID and CE parameters, respectively. Furthermore, native experiments involve adapting transfert and prepulse storage times (Note 8): set to $320 \mu \mathrm{s}$ and $15 \mu \mathrm{s}$, respectively. Concerning the source parameters, set the capillary voltage at $4 \mathrm{kV}$, the nebulizer at $0.4 \mathrm{bar}$, the dry gas at $4.0 \mathrm{~L} / \mathrm{min}$ and the temperature at $220^{\circ} \mathrm{C}$.

3. To perform the calibration, go to the "Calibration" tab and select the CsI reference file, then check that the calibration mode is on "Enhanced Quadratic Mode". Finally, click to "Calibrate" and accept the calibration.

\subsubsection{Exactive Plus EMR}

1. Using the HESI source and the $500 \mu \mathrm{L}$ Hamilton $^{\mathrm{TM}}$ syringe, deliver cesium iodide calibration mix (see 2.2) with a flow rate set to $10 \mu \mathrm{L} / \mathrm{min}$.

2. In the MS Tune page manually set the following parameters: 
Operate the instrument in positive mode with a $\mathrm{m} / \mathrm{z}$ range from 1,000 to 20,000 . Apply $25 \mathrm{eV}$ and $100 \mathrm{eV}$ for the CID and CE parameters, respectively. The source temperature is set at $250^{\circ} \mathrm{C}$, the capillary voltage is set to $4 \mathrm{kV}$ and the gas flows is set to $10 \mathrm{u}$.a. The trapping gas pressure is set to $7 \mathrm{u}$.a. Set the ion optics (injection, inter and bent flatapoles) at $4 \mathrm{~V}$, the nominal resolution at 17,500 and activate the EMR mode.

3. To perform the calibration, wait for a stable TIC (<12\%) then select "Calibrate" and check "EMR MS Mass Calibration (pos)".

3.5 High mass detection: Analysis of E. coli RNA polymerase on a modified ESI-TOF (LCT)

1. Desalt approximatively $100 \mu \mathrm{L}$ of $E$. coli RNA polymerase [17] at $30 \mu \mathrm{M}$ in 500 $\mathrm{mM}$ ammonium acetate at $\mathrm{pH} 6.9$ as explained in 3.2 using a Vivaspin ${ }^{\mathrm{TM}} 100 \mathrm{kDa}$ cut-off membrane at $15,000 \mathrm{~g}$ and $+4^{\circ} \mathrm{C}$.

2. Infuse the sample at $5 \mu \mathrm{M}$ with the TriVersa Nanomate ${ }^{\mathrm{TM}}$ (see 3.3).

3. Start with the same parameters as the ones used for Csl calibration but set the cone voltage to $150 \mathrm{~V}$ and the extraction cone to $50 \mathrm{~V}$. Increase the backing pressure up to $7 \mathrm{mbar}$ (Note 7). Adjust the pressure inside the first hexapole ion guide to 0.11 mbar using argon (available for the upgraded LCT) in order to optimise the transmission of high molecular species for native MS application (Note 9).

4. Start a $2 \mathrm{~min}$ acquisition in the 1,000 to $20,000 \mathrm{~m} / \mathrm{z}$ range.

5. The corresponding smoothed full mass spectrum is presented in Fig.1A and the corresponding deconvoluted spectrum in Fig.1B. In order to perform this deconvolution with UniDec [18,19] (http://unidec.chem.ox.ac.uk/), first export the spectrum list (EditlCopy spectrum list), then paste it in a text editor and save it as a .txt file. Import the .txt file in the UniDec software. Process the data with the following parameters: m/z range 1000 to 12,000 Th; Subtract Curved: 0; Gaussian Smoothing: 10; Bin Every: 10. Deconvolute the processed spectrum with the following parameters: Charge Range: 20 to 50; Mass Range: 20,000 to 500,000 Da; Sample Mass Every 1 Da; Peak FWHM 15 Th; Peak Shape Function: Gaussian.Detect and label the deconvoluted species with the following parameters: Peak Detection Range: 50; Peak Detection Threshold: 0.1; Peak Normalization: Max. As shown in Fig1, the hetero-oligomer of $E$. coli RNA polymerase $(390,315 \mathrm{Da})$ composed of five subunits and the $\alpha$-subunits $(36,509$ Da) species are detected. 

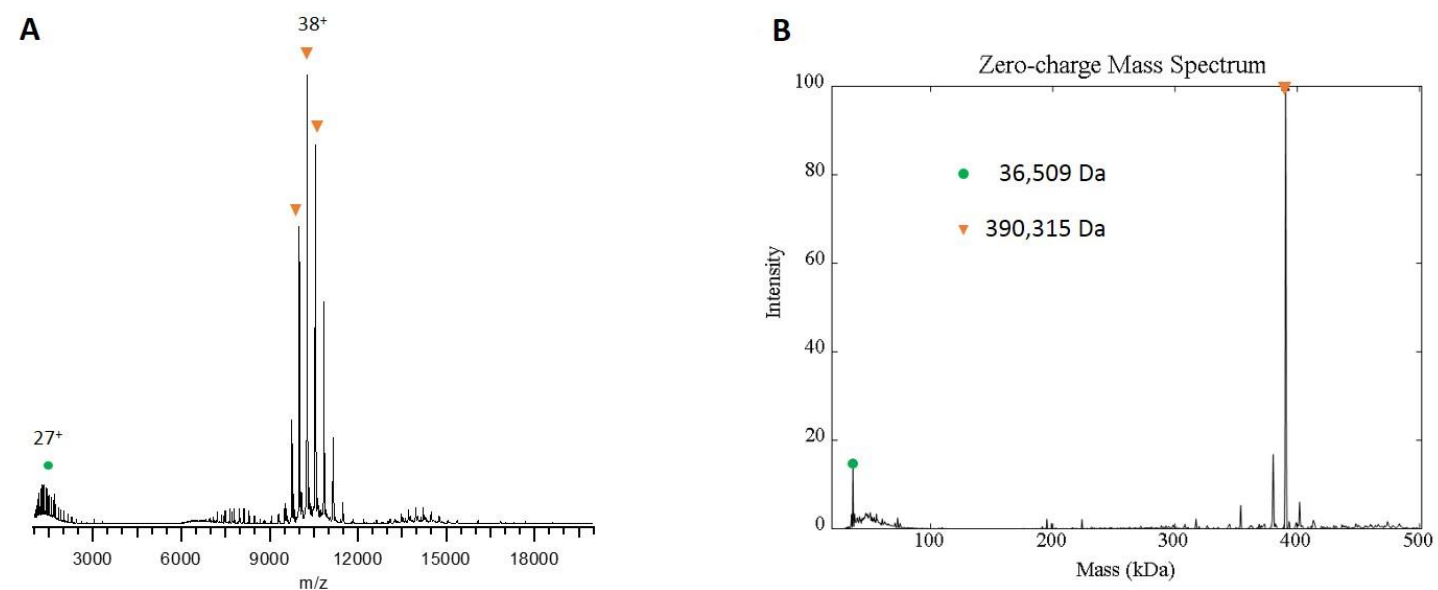

Fig.1. Native MS analysis of the E. coli RNA polymerase complex. A Full MS spectrum of $E$. coli RNA polymerase complex showing charged states $35+$ to $41+$ in the 9,000 to $12,000 \mathrm{~m} / \mathrm{z}$ range corresponding to the hetero-oligomer composed of five subunits (orange triangle) and $16+$ to $33+$ under $\mathrm{m} / \mathrm{z} 2,500$ corresponding to the $\alpha$-subunit (green circle). B Non denaturing mass spectrum of $E$. coli RNA polymerase after deconvolution with UniDec highlights the presence of the hetero-oligomeric protein $(390,315 \mathrm{Da})$ and the monomeric $\alpha$-subunit (36,509 Da).

3.6 Native MS analysis of the CDK-activating kinase (CAK) complex on a hybrid Synapt HDMS Q-TOF platform

1. Desalt $20 \mu \mathrm{l}$ of recombinant CAK [20] at $20 \mu \mathrm{M}$ in $200 \mathrm{mM}$ ammonium acetate supplemented with $0.02 \%$ n-Dodecyl $\beta$-D-maltoside (Note 10), as explained in 3.1

2. Connect the TriVersa Nanomate ${ }^{T M}$ as explained in 3.3.

3. In MassLynx MS Tune window manually set the following parameters:

Operate the instrument in positive and sensitivity modes with a $\mathrm{m} / \mathrm{z}$ range from 1,000 to 10,000 (Note 11).

Nanoflow+ panel: Sampling Cone: $175 \mathrm{~V}$ (Note 12). Extraction cone: $5 \mathrm{~V}$. Source Temperature: $90^{\circ} \mathrm{C}$.

Instrument: Increase the backing pressure up to 6 mbar (Note 7). Trap Collision Energy is turned on (75V) and Transfer Collision Energy is turned off (2V by default) (Note 13). Trap gas flow (argon) is set to $4.5 \mathrm{~mL} / \mathrm{min}$.

Save these parameters as an .ipr file.

4. Press "acquire" to start a 2 min TOF-MS acquisition in the $1,00-10,000 \mathrm{~m} / \mathrm{z}$ range.

5. The corresponding averaged and smoothed (20 times) raw data is represented in Fig.2A.

6. Manual or software-driven (see 3.5.5) deconvolution of the data identifies different species corresponding to the three monomers of the CAK complex: namely Cdk7 (MW: 40.1 kDa), Cyclin-H (MW: 37.7 kDa) and MNAT1 (MW: 35.9 kDa) (Fig.2B and C). A species corresponding to the heterodimer Cdk7-Cyclin-H at $77.9 \mathrm{kDa}$ is visible, confirming their direct interaction. Finally, the physiologically active heterotrimeric CAK is identified at $113.9 \mathrm{kDa}$. 

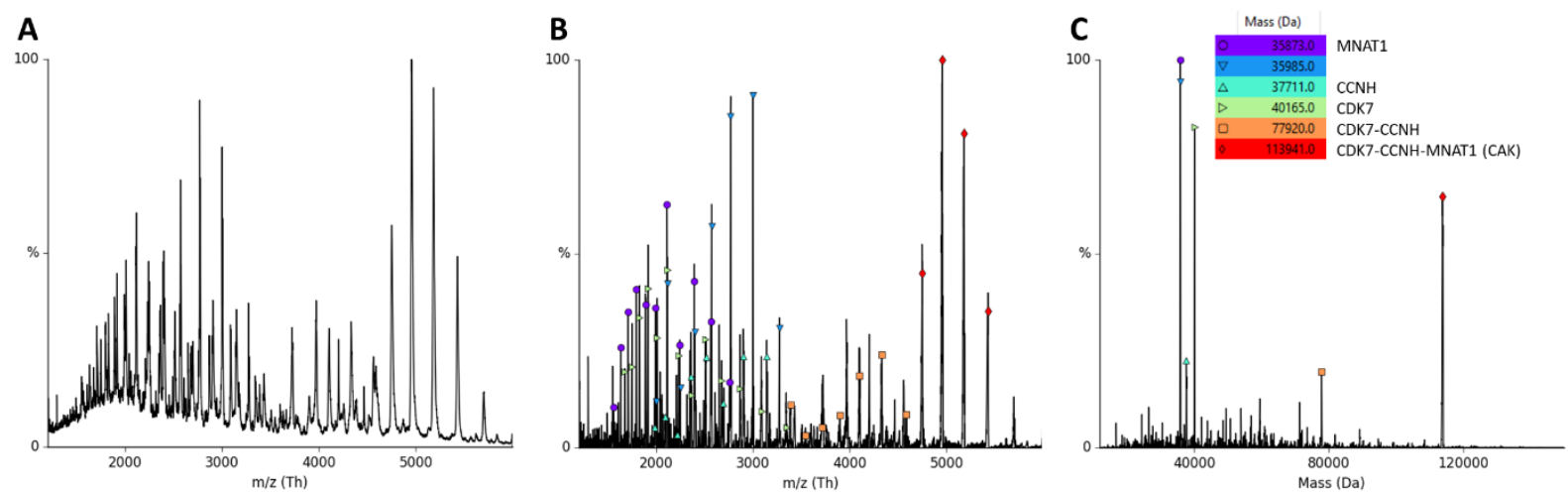

Fig.2. Native MS spectrum of the recombinant CDK-activating kinase complex desalted on a Micro Bio-Spin ${ }^{\mathrm{TM}} 6$ column. MS spectrum A before and B after Data Processing; and $\mathbf{C}$ after deconvolution in UniDec.

3.7 Determination of the protein oligomeric states by native MS analysis by direct infusion on a $\mathrm{Q}$-Exactive ${ }^{\mathrm{TM}}$ Biopharma Orbitrap platform

3.6.1 The trichothiodystrophy group A protein (TTD-A or p8)

1. Desalt $20 \mu \mathrm{l}$ of recombinant $\mathrm{p} 8$ [21] at $24 \mu \mathrm{M}$ as explained in 3.1 .

2. Connect the TriVersa Nanomate ${ }^{T M}$ to the $\mathrm{Q}$-Exactive ${ }^{\mathrm{TM}}$ Biopharma Orbitrap as explained in 3.3

3. In Excalibur Tune window manually set the following parameters:

Operate the instrument in positive mode with an $\mathrm{m} / \mathrm{z}$ range from 200 to 4,000 .

Intact protein mode: off; HRM mode: off; resolution: 120,000; Micro Scan Count: 1; Max. Ion Time: 100 ms; AGC target: 1e6, S-Lens RF Level: 40, Capillary Temperature: $275^{\circ} \mathrm{C}$, Capillary Voltage: $1.5 \mathrm{kV}$.

Save these parameters as an .mstune file.

4. Start a 2 min acquisition in the $200-4,000 \mathrm{~m} / \mathrm{z}$ range.

5. The corresponding averaged raw data is represented in Fig.3A

6. Manual or software-driven (see 3.5.5) deconvolution of the data identifies different species corresponding to the monomeric $(\mathrm{MW}=8272 \mathrm{Da})$ and dimeric $(\mathrm{MW}=16544$ Da) p8 protein (Fig.3B). A close-up view of the peak at $2069 \mathrm{~m} / \mathrm{z}(42,000$ resolution) shows isotopic distributions corresponding to both the $4+$ charged state of the monomer and the $8+$ charged state of the dimer (Fig.3A, inset). The effective resolution ranges from $35,000(\mathrm{~m} / \mathrm{z} 2758)$ to $56,000(\mathrm{~m} / \mathrm{z} 1035)$.
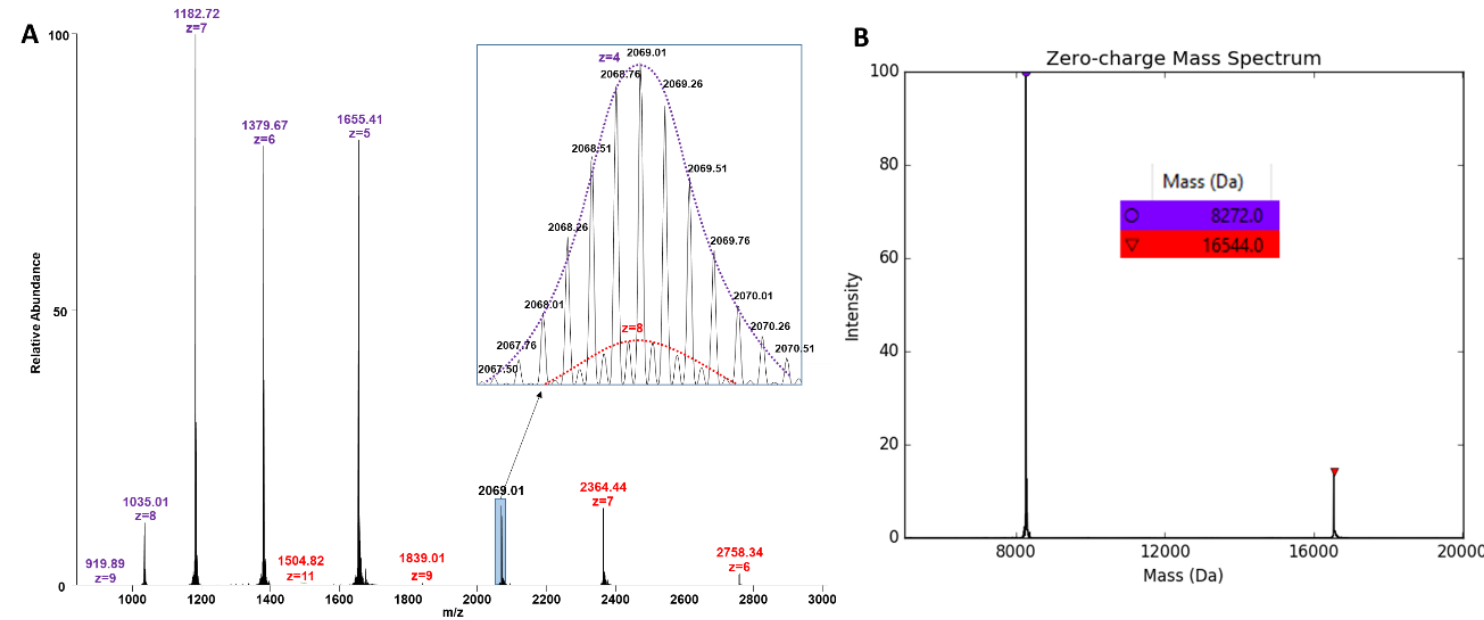
Fig.3. Native MS analysis of the p8 subunit from the human TFIIH complex A Raw MS spectrum of p8 showing charged states $4+$ to $9+$ corresponding to the monomer (purple) and 6+ to $11+$ corresponding to the dimer (red). The inset shows a close-up view of the 2069.01 peak, revealing an overlap of the monomeric 4+ and dimeric 8+ charged states. B Native MS spectrum of p8 after deconvolution with UniDec, showing the presence of monomeric $(8272 \mathrm{Da})$ and dimeric $(16544 \mathrm{Da})$ species.

\subsubsection{The Yeast Alcohol Dehydrogenase (ADH)}

1. Weight $1.6 \mathrm{mg}$ of alcohol dehydrogenase from Saccharomyces Cerevisiae (Sigma-Aldrich). Resuspend in $280 \mu \mathrm{L}$ of $200 \mathrm{mM}$ ammonium acetate to reach a tetrameric concentration of $40 \mu \mathrm{M}$.

2. Connect the TriVersa Nanomate ${ }^{\mathrm{TM}}$ to the $\mathrm{Q}$-Exactive ${ }^{\mathrm{TM}}$ Biopharma Orbitrap as explained in 3.4

3. In Excalibur Tune window manually set the following parameters:

Operate the instrument in positive mode with an $\mathrm{m} / \mathrm{z}$ range from 2,500 to 8,000 .

Intact protein mode: off; HRM mode: on; resolution: 15,000; Micro Scan Count: 10; Max. Ion Time: 200 ms; AGC target: 3e6, S-Lens RF Level: 200, Capillary Temperature: $320^{\circ} \mathrm{C}$, Capillary Voltage: $4.4 \mathrm{kV}$.

Save these parameters as an .mstune file.

4. Start a $2 \mathrm{~min}$ acquisition in the $2,500-8,000 \mathrm{~m} / \mathrm{z}$ range.

5. The corresponding averaged raw data is represented in Fig.4A

6. Manual or software-driven (see 3.5.5) deconvolution of the data identifies different species corresponding to the monomeric ( $\mathrm{MW}=36,879 \mathrm{Da})$ and tetrameric $(\mathrm{MW}=147,516 \mathrm{Da}) \mathrm{ADH}$ protein (Fig.4B). The effective resolution ranges from $2,000(\mathrm{~m} / \mathrm{z} 5,674)$ to $4,600(\mathrm{~m} / \mathrm{z} 2,844)$.
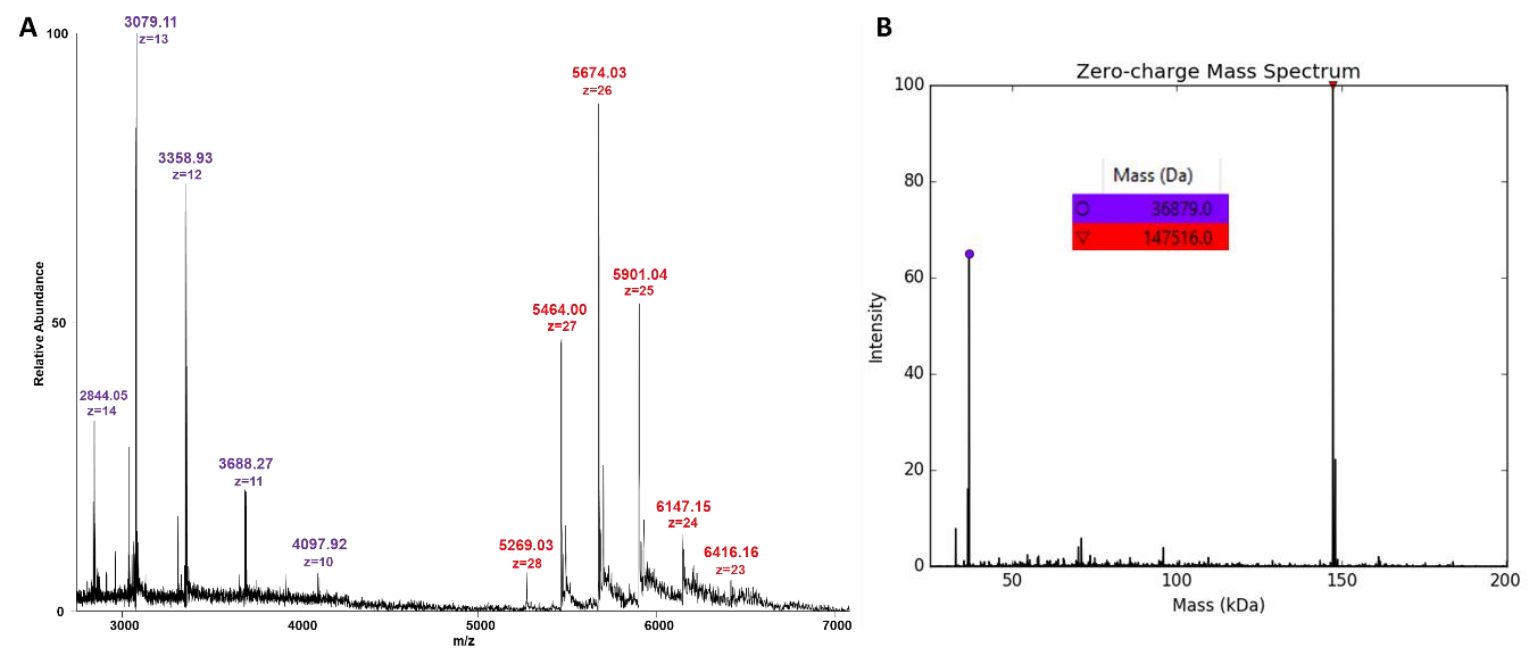

Fig.4. Native MS analysis of the of the ADH from Saccharomyces cerevisiae A Raw MS spectrum of the ADH showing charged states $10+$ to $14+$ corresponding to the monomer (purple) and $23+$ to $28+$ corresponding to the tetramer (red). B Native MS spectrum of p8 after deconvolution with UniDec, showing the presence of monomeric $(36,879 \mathrm{Da})$ and tetrameric $(147,516 \mathrm{Da})$ species.

3.8 SEC Native MS coupling (ADH)

1. Connect the ACQUITY UPLC H-Class Bio to the SynaptG2Si.

2. Connect the ACQUITY UPLC Protein BEH SEC Column (200 $\AA, 1.7 \mu \mathrm{m}, 4.6 \mathrm{~mm}$ $x 150 \mathrm{~mm}$ ) and equilibrate with $200 \mathrm{mM}$ ammonium acetate at $300 \mu \mathrm{L} / \mathrm{min}$. 
3. Weight $1.6 \mathrm{mg}$ of alcohol dehydrogenase from Saccharomyces Cerevisiae (Sigma-Aldrich). Resuspend in $280 \mu \mathrm{L}$ of $200 \mathrm{mM}$ ammonium acetate to reach a tetrameric concentration of $40 \mu \mathrm{M}$.

4. In MassLynx, setup an MS file with the following parameters:

Start Time: 0 min; End Time: 10 min; Polarity: Positive; Analyser Mode: Sensitivity; Dynamic Range: Normal; Sensitivity: Normal; Low Mass: $1000 \mathrm{Da}$; High Mass: 10,000 Da; Scan Time: $1 \mathrm{sec}$ (Continuum); No Trap or Transfer CE.

5. In MassLynx, setup an Inlet file with the following parameters: Flow rate 200 $\mu \mathrm{L} / \mathrm{min}$ with $100 \%$ solvent $\mathrm{A}$ (200 mM ammonium acetate) for $10 \mathrm{~min}$.

6. In MassLynx MS Tune windows manually set the following parameters:

Nanoflow+ panel: Capillary: 3 kV; Sampling Cone: 150 V. Source Offset: 80V. Source Temperature: $100^{\circ} \mathrm{C}$. Cone Gas: 50 L/h; Nano Flow Gas: 0 Bar; Purge Gas: $100 \mathrm{~L} / \mathrm{h}$.

Instrument: Trap and Transfer Collision Energy are turned off (4V and $2 \mathrm{~V}$, respectively by default).

Save these parameters as an MS tune file (.ipr file).

7. In MassLynx, create a sample list with the corresponding MS file, Inlet file, MS tune file. Specify the sample position (Bottle) and the volume to be injected (10 $\mu \mathrm{L})$.

8. Start the acquisition.

9. The chromatogram shows two main peaks at $6.14 \mathrm{~min}$ and $7.32 \mathrm{~min}$ (Fig.5A), corresponding to the tetramer (Fig.5C) and monomer (Fig.5B) of the ADH, respectively.
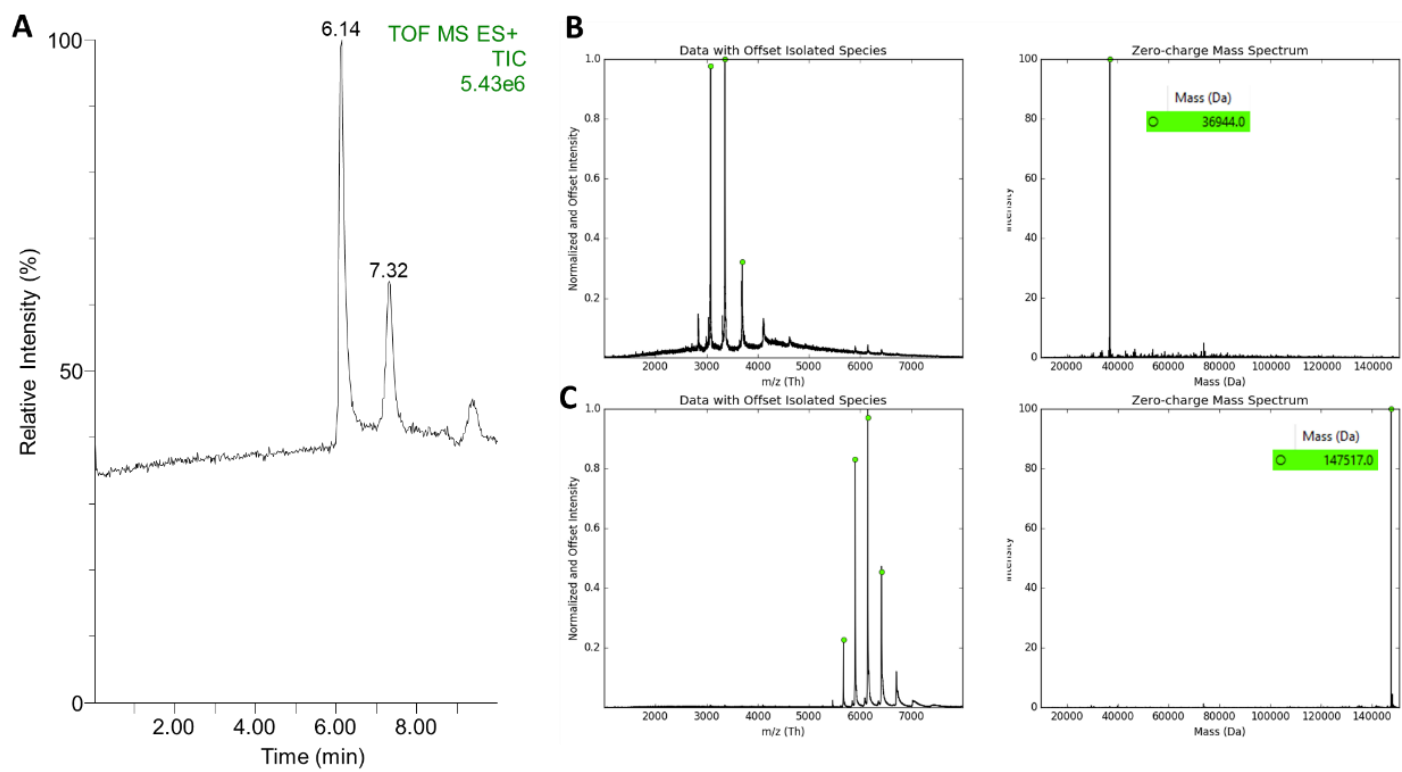

Fig.5. SEC-Native MS analysis of the ADH from Saccharomyces cerevisiae A Total Ion Chromatogram (TIC) corresponding to the SEC separation of the monomer and tetramer of the ADH. B Native MS spectrum of the monomer $(36.9 \mathrm{kDa})$ before (left) and after (right) deconvolution with UniDec. C Native MS spectrum of the tetramer (147.5 kDa) before (left) and after (right) deconvolution with UniDec.

3.9 Homo-oligomeric Concanavalin A analysis on a high-resolution Q-TOF mass spectrometer - Maxis II 
1. Resuspend $1.5 \mathrm{mg}$ of Concanavalin A from Canavalia ensiformis (Jack bean, SigmaAldrich reference $\mathrm{n}^{\circ} \mathrm{C} 5275$ ) in $200 \mu \mathrm{L}$ of $10 \mathrm{mM}$ ammonium acetate at $\mathrm{pH} 6.8$ to reach a concentration around $50 \mu \mathrm{M}$ for the tetrameric species.

2. Desalt $100 \mu \mathrm{L}$ of the protein (see 3.2) on a Vivaspin ${ }^{\mathrm{TM}} 10 \mathrm{kDa}$ cut-off membrane (6-8 cycles at $15,000 \mathrm{~g}$ and $+4^{\circ} \mathrm{C}$ during 8-10 $\mathrm{min}$ ).

3. Connect the TriVersa Nanomate ${ }^{\mathrm{TM}}$ to the mass spectrometer. Infuse the protein at 10 $\mu \mathrm{M}$.

4. In the tune page, use the same parameters used for Csl calibration except for the is CID that should be set at $35 \mathrm{eV}$.

5. Start a $2 \mathrm{~min}$ acquisition in the 1,000 to $8,000 \mathrm{~m} / \mathrm{z}$ range.

6. The average smoothed mass spectrum is represented in Fig.6A. The corresponding deconvoluted spectrum is obtained after UniDec processing (Fig.6B, see 3.5.5) and allows the identification of Concanavalin A tetrameric species at 102,707 Da.

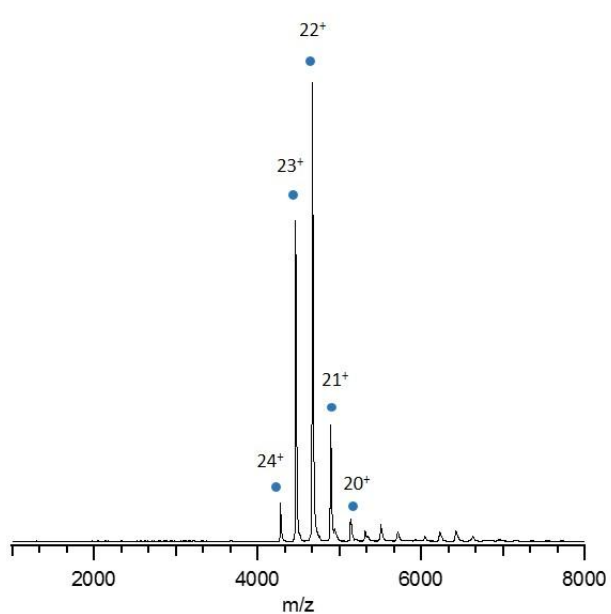

B

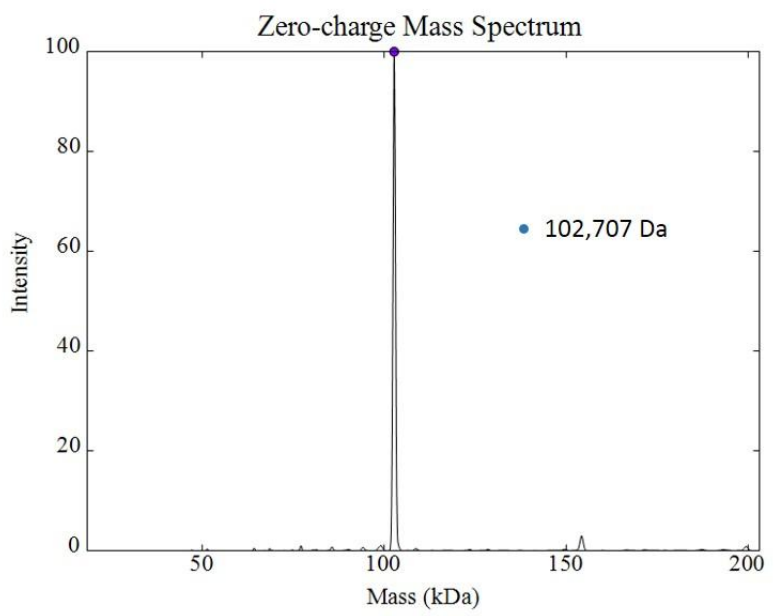

Fig.6. Native MS analysis of Concanavalin A from Canavalia ensiformis protein. A Full MS spectrum of Concanavalin A showing charged states $24+$ to $20+$ in the $\mathrm{m} / \mathrm{z}$ range from 4,000 to 5,500 corresponding to the homo-oligomeric protein (blue circle). B Non denaturing mass spectrum of Concanavaline A after deconvolution with UniDec highlights the tetrameric state of the protein complex $(102,707 \mathrm{Da})$.

3.10 Protein/DNA complex analysis on a Q-TOF mass spectrometer - Synapt G2 HDMS

1. Desalt $50 \mu \mathrm{L}$ of ERRa DBD-BE26PSIR3 complex [22] at $28 \mu \mathrm{M}$ on a Zeba ${ }^{\mathrm{TM}}$ spin column equilibrated with $200 \mathrm{mM}$ ammonium acetate at $\mathrm{pH} 7.1$ as explained in section 3.1.

2. Use the TriVersa Nanomate ${ }^{\mathrm{TM}}$ (see 3.3) coupled to the mass spectrometer and infuse the protein complex at $5 \mu \mathrm{M}$.

3. In the Tune page, start with the parameters used for the CsI calibration and adapt the cone voltage at $140 \mathrm{~V}$, the extraction cone at $5 \mathrm{~V}$ and the backing pressure at 6 mbar (Note 7).

4. Start a 2 min acquisition in the 1,000 to $6,000 \mathrm{~m} / \mathrm{z}$ range.

5. The average full MS spectrum obtained is presented in Fig.7.A.

6. The corresponding deconvoluted spectrum (see section 3.5.5) is represented in Fig.7.C and confirms the 1:1 stoichiometry between protein and DNA species $(27,892.5 \mathrm{Da}$ for full length DNA). Other species corresponding to truncated DNA 
associated to the protein with a 1:1 stoichiometry are also detected $(27,740.6 \mathrm{Da}$ and 27,586.3 Da).

A

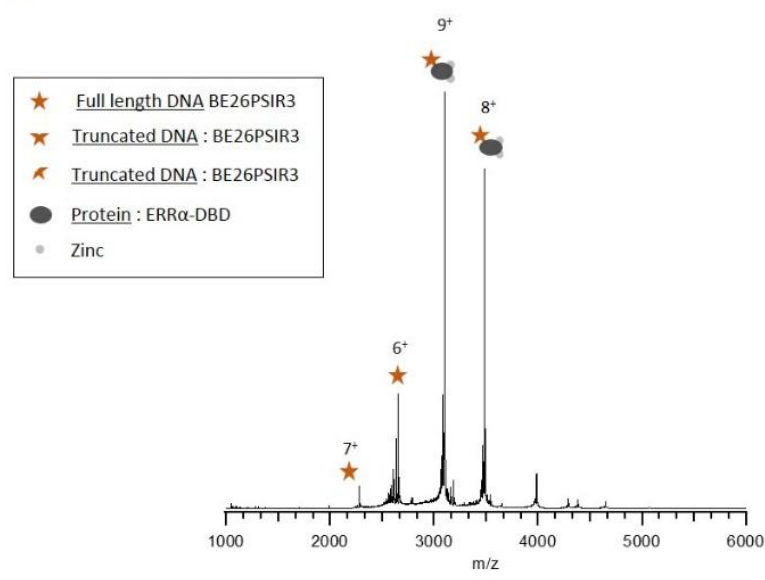

B

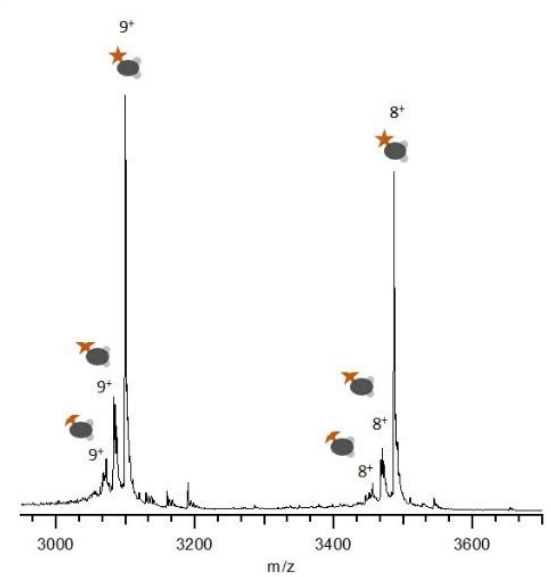

\section{C}

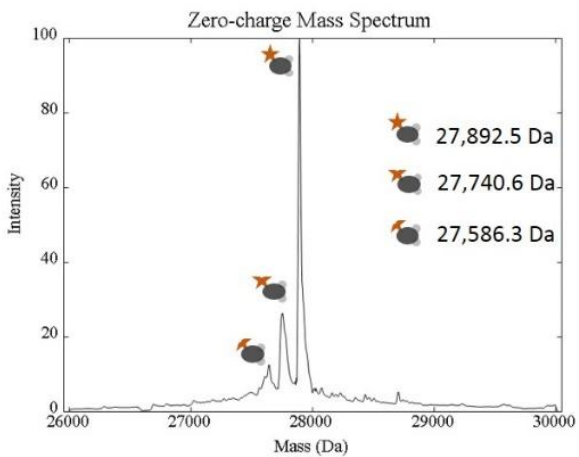

Fig.7. Native MS analysis of the ERRa DBD-BE26PSIR3 complex. A Full MS spectrum of protein/DNA complex. Two charge states distributions in the 2,000 to $4,000 \mathrm{~m} / \mathrm{z}$ range are present, corresponding firstly to the $6+$ and $7+$ charge states of DNA alone in the 2,000 to $3,000 \mathrm{~m} / \mathrm{z}$ range and secondly to the $9+$ and $8+$ charge states of the protein/DNA complex in the 3,000 to $3,800 \mathrm{~m} / \mathrm{z}$ range. B Zoom in the 3,000 to $3,600 \mathrm{~m} / \mathrm{z}$ range showing the protein/DNA complex 9+ and 8+ charge states revealing the presence of two truncated DNA species. C The associated deconvolution of native mass spectrum with UniDec software highlights a 1:1 stoichiometry for the protein/DNA complex $(27,892.5$ $\mathrm{Da})$ and confirms the presence of two truncated DNA species which are also able to interact with the protein $(27,740.6 \mathrm{Da}$ and $27,586.3 \mathrm{Da})$.

3.11 High molecular weight homo-oligomeric protein on a high resolution Orbitrap mass spectrometer - Exactive Plus EMR

1. Use the freshly prepared and desalted GroEL protein (see 2.4). 
2. Connect the TriVersa Nanomate ${ }^{\mathrm{TM}}$ (see 3.3) to the mass spectrometer. Infuse the sample concentrated at $5 \mu \mathrm{M}$ of oligomer.

3. In the Tune page, set the following parameters: Positive mode with a 1,000 to $20,000 \mathrm{~m} / \mathrm{z}$ range. Activate the EMR mode and set the trapping gas pressure at 7 u.a., the ion optics at $4 \mathrm{~V}$ (inter, injection and bent flatapoles), the S-lens RF voltage at $200 \mathrm{~V}$, the temperature at $250^{\circ} \mathrm{C}$, the fragmentation parameters at 25 $\mathrm{eV}$ and $150 \mathrm{eV}$ for CID and CE values, respectively. Select a nominal resolution of 17,500 .

4. Start a 2 min acquisition with a stable TIC.

5. The resulting averaged mass spectrum is presented in Fig.8A (full mass range). Fig.8B is a zoom where ions signal are detected between $11,000-13,000 \mathrm{~m} / \mathrm{z}$. After data processing (see 3.5.5), a unique species corresponding to the 14-mer complex is identified (Fig.8C) at $801.6 \mathrm{kDa}$.

A

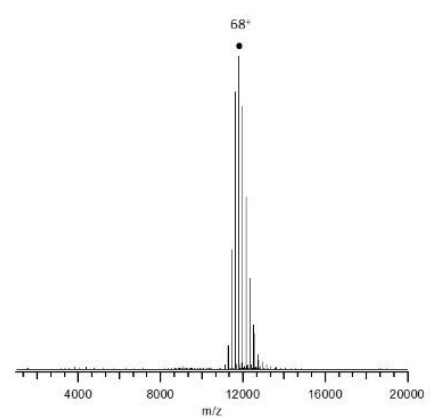

B

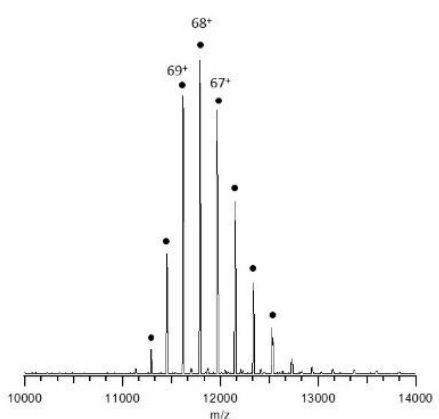

C

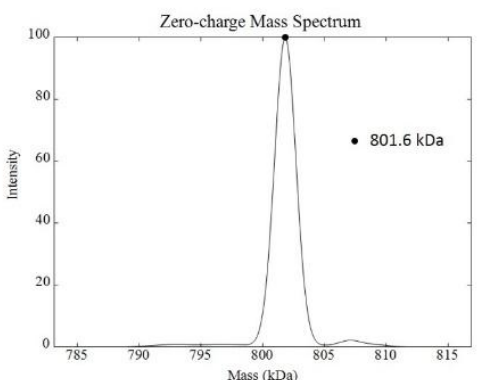

Fig.8. Native MS analysis of Chaperonin 60 (GroEL) complex. A Full MS spectrum of GroEL complex showing a unique charge states distribution around $\mathrm{m} / \mathrm{z} 12,000$. B Zoom in the 10,000 to $14,000 \mathrm{~m} / \mathrm{z}$ range where charge states $64+$ to $71+$ of the protein complex are detected. C Associated deconvolution obtained after data processing using UniDec software in the $785 \mathrm{kDa}$ to $815 \mathrm{kDa}$ mass range, showing one species corresponding to the 14-mer homo-complex at $801.6 \mathrm{kDa}$.

\section{Notes}

1. The optimum ammonium acetate concentration is protein-dependent and can be optimized by testing concentrations ranging from $10 \mathrm{mM}$ up to $1 \mathrm{M}$. If needed, volatile additives can be added, such as dithiothréitol or tris(2-carboxyethyl) phosphine for disulfide bond reduction, imidazole, some detergents (see Note X) or metallic ions in a volatile buffer (calcium acetate, zinc acetate...).

2. Volatility of the buffer is key for native MS. Beware to avoid any trace of nonvolatile salts such as sodium chloride. Ammonium acetate resuspended at 200 $\mathrm{mM}$ in water is usually at $\mathrm{pH} 6.9$. If you want to adjust $\mathrm{pH}$ below 6.9 , do not use $\mathrm{HCl}$ but formic acid or acetic acid instead. Alternatively, you can dilute a commercial 7.5 M ammonium acetate solution (Sigma). Conversely, to increase the $\mathrm{pH}$, use liquid $\mathrm{NH} 3$ and not $\mathrm{NaOH}$.

3. For smaller volumes, $7 \mathrm{~K}$ MWCO Zeba ${ }^{\mathrm{TM}}$ Micro Spin columns $(2-12 \mu \mathrm{L}$, ThermoFisher Scientific) can be used.

4. Do not forget to turn off the cooling of the plate after use of the nanomate. Otherwise, condensation will occur, water will fill the wells and the plate will have to be discarded the next day.

5. The gas pressure and voltage to apply are the main two parameters to adjust. The stability of the spray can be visualized in the Spray Optimization window, by 
pressing "Graph". If the intensity of the electrospray is dropping, incrementally increasing the gas pressure (no more than $0.5 \mathrm{psi}$ ) or the Voltage to apply (no more than $1.80 \mathrm{kV}$ ) might help. If the spray is not coming back, use another nozzle by pressing "Next Nozzle". Reducing the gas pressure and Voltage to apply while spraying usually results spray loss. The optimum Voltage to apply is protein-dependent and has to be carefully optimized, as higher values usually increase the ion transmission (more intense signal) and buffer removal (better resolved signal) but might result in complex dissociation. Ticking "Return unused sample to tray" enables to recover most of the sample after data acquisition.

6. Reference files for higher $\mathrm{m} / \mathrm{z}$ ranges can be custom made. In the case of Csl, increments of $+259.81 \mathrm{Da}$ can be directly added to the initial Csl calibration file.

7. The backing pressure is a key parameter on Waters instruments (LCT, Synapt), that needs to be optimized for each protein complex. Generally, this value is set around 6 mbar and can be adjusted if necessary. This is possible by adding a homemade system with two external valves that reduce the suction of the primary pump.

8. In order to optimally accumulate and transfer heavy ions, transfer time and prepulse storage time parameters should be increased compared to small ions analysis. These two parameters are linked but the transfer time has to be higher than the prepusle storage time.

9. Waters TOF or Q-TOF mass spectrometers can be upgraded (MS vision, the Netherlands) by modifying electronics and gas pressure in order to improve the transmission of high molecular mass species in non-denaturing conditions. On our upgraded LCT, the combination of an additional gas arrival (argon) in the first hexapole housing through a needle valve and the modification of different electronic parts (e.g. higher voltages applied to sample and extraction cones) result in an improvement of high molecular mass transmission. Typically, the sensitivity for GroEL $L_{14}$ analysis is increased six-fold by argon admission if the pressure is set around $4.10^{-2}$ mbar. A micro-Pirani gauge is installed to control the pressure applied

10. n-Dodecyl $\beta$-D-maltoside can be used at two-times the critical micellar concentration $(0.02 \%)$ in order to stabilize very labile soluble complexes. It can also be used, at the same concentration to spray membrane proteins $[\mathbf{2 3 , 2 4 ]}$.

11. The $\mathrm{m} / \mathrm{z}$ range on Waters $\mathrm{Q}-T O F$ depend on the type of Quadrupole that is installed: up to $16,000 \mathrm{~m} / \mathrm{z}$ for a $4,000 \mathrm{~m} / \mathrm{z}$ quadrupole, up to $32,000 \mathrm{~m} / \mathrm{z}$ for an $8,000 \mathrm{~m} / \mathrm{z}$ quadrupole and up to $128,000 \mathrm{~m} / \mathrm{z}$ for a $32,000 \mathrm{~m} / \mathrm{z}$ quadrupole.

12. The sample cone is a key parameter on Waters instruments (LCT, Synapt...), that needs to be optimized for each protein complex. Similarly, to the voltage applied to the nozzle of the TriVersa Nanomate ${ }^{T M}$, higher values usually increase the intensity of the signal and provide better resolved peaks by removing residual buffer. However, high sample cone values might result in complex dissociation. Here again, an optimum value has to be found that provides good signal without undermining the multiprotein complex integrity. A good strategy is to start with a maximum Sampling Cone voltage $(150 \mathrm{~V})$ and progressively reduce it by $10 \mathrm{~V}$ steps.

13. The trap collision energy is another key parameter on Waters Q-TOF. In the case of membrane proteins or very large multiprotein complexes (>500 kDa), increasing the trap collision energy might be helpful or even mandatory in order to thermodynamically cool down the ions (large complexes) or remove the remaining detergent molecules. Simultaneously and incrementally increasing the Trap gas flow (from $2 \mathrm{~mL} / \mathrm{min}$ up to $8 \mathrm{~mL} / \mathrm{min}$ ) might improve the transmission of these particular large or membrane protein complexes.

\section{Acknowledgement}


The authors would like to thank Arnaud Poterszman (CAK complex), Albert Weixlbaumer (E. coli RNA polymerase) and Isabelle Billas Massobrio (ERR complexes) from the IGBMC (Strasbourg, France) and Virginie Gervais \& Alain Milon from IPBS (Toulouse, France) for kindly providing samples. This work was supported by the French Ministry of Research (Investissements d'Avenir Program, Proteomics French Infrastructure, ANR-10-INBS-08) and the FEDER (Fonds Européens de Développement Régional), Toulouse Métropole and the Région Midi-Pyrénées.

\section{Rerefences}

1. Marcoux $\mathrm{J}$ and Robinson CV (2013) Twenty years of gas phase structural biology. Structure 21(9) : 1541-1550.

2. Ganem B (1991) Detection of Noncovalent Receptor-Ligand Complexes by Mass Spectrometry J. Am. Chem. Soc 113:6294-6296

3. Ganem B (1991) Observation of Noncovalent Enzyme-substrate and Enzyme-Product Complexes by Ion-Spray Mass Spectrometry J. Am. Chem. Soc 113:7818-7819

4. Katta V and Chait B (1991) Observation of the Hemoglobin Complex in Native Myoglobin by Electrospray-Ionization Mass Spectrometry J. Am. Chem. Soc 113:8534-8535

5. Nettleton EJ, Sunde M, Lai Z, Kelly JW, Dobson CM, Robinson CV. (1998) Protein subunit interactions and structural integrity of amyloidogenic transthyretins: evidence from electrospray mass spectrometry. J Mol Biol. 281(3):553-64.

6. Pinkse MWH, Heck AJR, Rumpel K, Pullen F. (2004) Probing noncovalent proteinligand interactions of the cGMP-dependent protein kinase using electrospray ionization time of flight mass spectrometry. J Am Soc Mass Spectrom. 15(10):1392-1399.

7. Sobott F, Hernández H, McCammon MG, Tito MA, Robinson CV. (2002) A tandem mass spectrometer for improved transmission and analysis of large macromolecular assemblies. Anal Chem. 15;74(6):1402-7.

8. Rose RJ, Damoc E, Denisov E, Makarov A, Heck AJ. (2012) High-sensitivity Orbitrap mass analysis of intact macromolecular assemblies. Nat Methods. 9(11):1084-6.

9. Andersson FI, Tryggvesson A, Sharon M, Diemand AV, Classen M, Best C, Schmidt R, Schelin J, Stanne TM, Bukau B, Robinson CV, Witt S, Mogk A, Clarke AK. (2009) Structure and function of a novel type of ATP-dependent Clp protease. J Biol Chem. 15;284(20):13519-32.

10. Sharon M, Mao H, Boeri Erba E, Stephens E, Zheng N, Robinson CV. (2009) Symmetrical modularity of the COP9 signalosome complex suggests its multifunctionality. Structure. 17(1):31-40.

11. Martinez-Zapien D, Saliou JM, Han X, Atmanene C, Proux F, Cianférani S, DockBregeon AC. (2015) Intermolecular recognition of the non-coding RNA 7SK and HEXIM protein in perspective. Biochimie. 117:63-71.

12. Saliou JM, Manival X, Tillault AS, Atmanene C, Bobo C, Branlant C, Van Dorsselaer A, Charpentier B, Cianférani S. (2015) Combining native MS approaches to decipher archaeal box H/ACA ribonucleoprotein particle structure and activity. Proteomics. 15(16):2851-61.

13. Barrera NP1, Di Bartolo N, Booth PJ, Robinson CV. (2008) Micelles protect membrane complexes from solution to vacuum. Science. 321(5886):243-6.

14. Chorev DS, Baker LA, Wu D, Beilsten-Edmands V, Rouse SL, Zeev-Ben-Mordehai T, Jiko C, Samsudin F, Gerle C, Khalid S, Stewart AG, Matthews SJ, Grünewald K, Robinson CV. (2018) Protein assemblies ejected directly from native membranes yield complexes for mass spectrometry. Science. 362(6416):829-834.

15. Gan J, Ben-Nissan G, Arkind G, Tarnavsky M, Trudeau D, Noda Garcia L, Tawfik DS, Sharon M. (2017) Native Mass Spectrometry of Recombinant Proteins from Crude Cell Lysates. Anal Chem. 89(8):4398-4404. 
16. van de Waterbeemd $M$, Tamara $S$, Fort $K L$, Damoc $E$, Franc $V$, Bieri $P$, Itten $M$, Makarov A, Ban N, Heck AJR. (2018) Dissecting ribosomal particles throughout the kingdoms of life using advanced hybrid mass spectrometry methods. Nat Commun. 27;9(1):2493.

17. Twist KA, Husnain SI, Franke JD, Jain D, Campbell EA, Nickels BE, Thomas MS, Darst SA, Westblade LF (2011). A novel method for the production of in vivo-assembled, recombinant Escherichia coli RNA polymerase lacking the a C-terminal domain. Protein Sci. 20(6), 986-995.

18. Marty MT, Baldwin AJ, Marklund EG, Hochberg GK, Benesch JL, Robinson CV (2015) Bayesian deconvolution of mass and ion mobility spectra: from binary interactions to polydisperse ensembles. Anal Chem. 87(8):4370-6

19. Reid DJ, Diesing JM, Miller MA, Perry SM, Wales JA, Montfort WR, Marty MT (2019) MetaUniDec: High-Throughput Deconvolution of Native Mass Spectra. J Am Soc Mass Spectrom. 30(1):118-127.

20. Radu L, Schönwetter E, Braun C, Marcoux J, Kölmel W, Schmitt DR, Kuper J, Cianferani S, Egly JM, Poterszman A, Kisker C (2017) The intricate network between the p34 and p44 subunits is central to the activity of the transcription/DNA repair factor TFIIH. Nucleic Acids Research 45(18) : 10872-10883

21. Gervais V, Muller I, Mari PO, Mourcet A, Movellan K, Ramos P, Marcoux J, Guillet V, Javaid S, Burlet-Schiltz O, Czaplicki G, Milon A, Giglia-Mari G (2018) Small molecule-based targeting of TTD-A dimerization to control TFIIH transcriptional activity represents a potential strategy for anticancer therapy. Journal of Biological Chemistry 293(39):14974-14988

22. Mohideen-Abdul K, Tazibt K, Bourguet $M$, Hazemann I, Lebars I, Takacs $M$, Cianférani S, Klaholz BP, Moras D, Billas IML (2017) Importance of the Sequence-Directed DNA Shape for Specific Binding Site Recognition by the Estrogen-Related Receptor Front Endocrinol (Lausanne). 8: 140.

23. Marcoux J, Wang S, Politis A, Reading E, Ma J, Biggins P, Zhou M, Tao H, Zhang Q, Chang G, Morgner N, Robinson CV (2013) Mass spectrometry reveals synergistic binding of nucleotides, lipids and drugs to a multidrug resistance efflux pump. Proceedings of the National Academy of Sciences 110(24) : 9704-9709.

24. Laganowsky A, Reading E, Hopper JT, Robinson CV (2013) Mass spectrometry of intact membrane protein complexes. Nat Protoc. 8(4):639-51. 